Document downloaded from:

http://hdl.handle.net/10251/72353

This paper must be cited as:

Tavares De Araujo Cesariny Calafate, CM.; Tornell, SM.; Arlandis, J. (2016). A comparative study of two automated workgroup composition strategies. En INTED2016 Proceedings. IATED Digital Library. 5890-5899. doi:10.21125/inted.2016.0409.

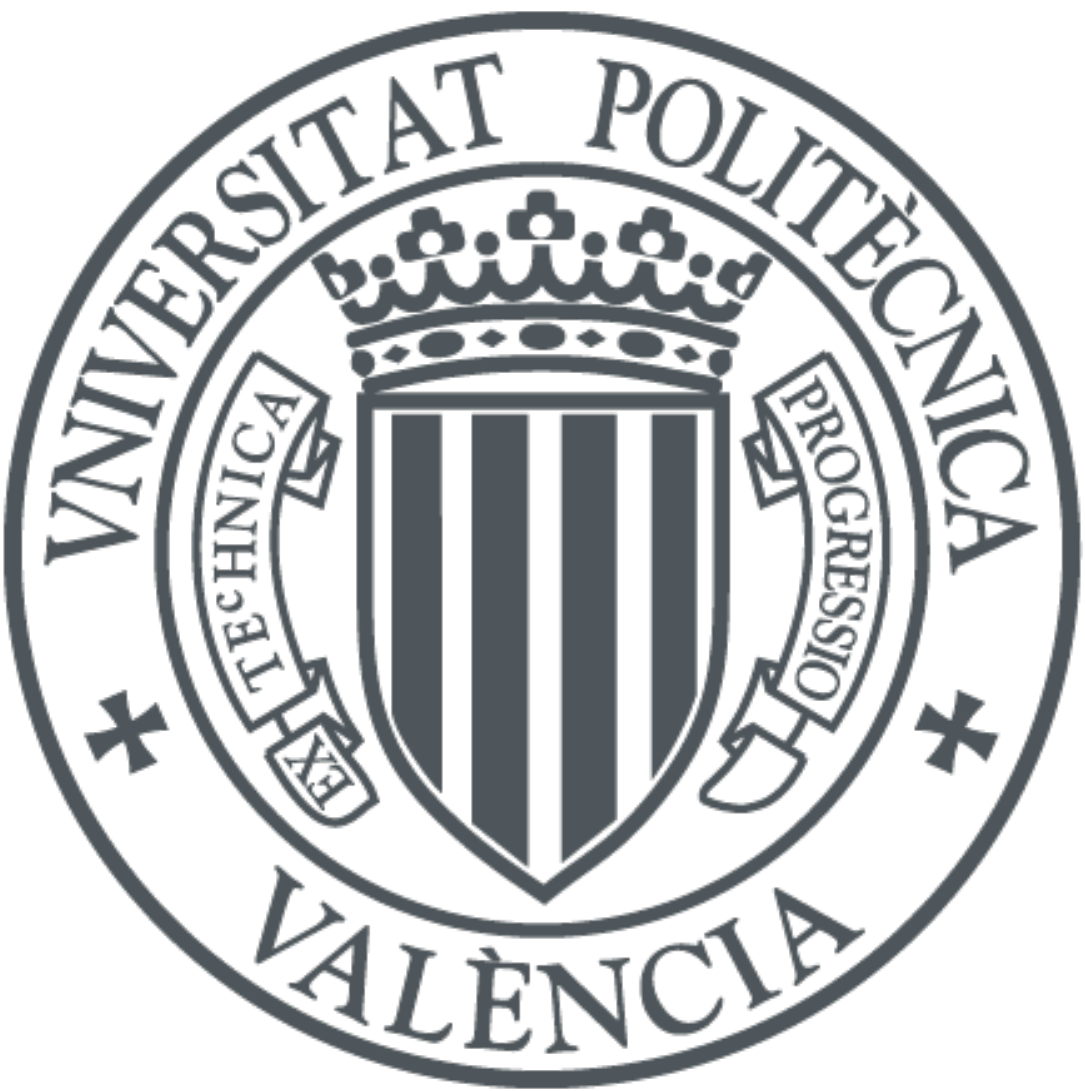

The final publication is available at

https://library.iated.org/publications/INTED2016

Copyright IATED Digital Library

Additional Information 


\title{
A COMPARATIVE STUDY OF TWO AUTOMATED WORKGROUP COMPOSITION STRATEGIES
}

\author{
Carlos T. Calafate, Sergio Martínez, Joaquim Arlandis \\ Department of Computer Engineering (DISCA) \\ School of Informatics (ETSINF) \\ Universitat Politècnica de València (SPAIN) \\ E-mail: calafate@disca.upv.es, sermarto@upv.es, jarlandi@disca.upv.es
}

\begin{abstract}
Nowadays, the professional environment of leading companies requires multidisciplinary teams to be created, including both internal and external experts, to adequately face the challenges of a fast-evolving and complex market. For newcomers, this situation can be difficult to handle if no previous experiences allowed preparing them for those situations. This is where college education finds its place, and in fact the curricula of different university careers are being updated to include more transversal competences like leadership and cooperation skills within groups. However, such efforts still remain at an amateur level in most cases due to lack of specific expertise by the majority of instructors, due to limitations in terms of creating actual multidisciplinary groups, and due to the little resources available to maximize the benefits of such experiences. Students also show little involvement in this issue, typically opting for approaches that minimize their efforts. Thus, simple and yet effective strategies that can be helpful for instructors to make a meaningful change to the current status quo are necessary. To address this need, in this paper we present the results of a 2-year study where students were forced to team up with other partners based on the results of a computer networking skills-ranking exam. In the first experiment, groups where formed by students achieving a similar performance (homogeneous), while in the second experiment groups were formed so that the average score of group members was the same (mostly heterogeneous). Through detailed survey results taken by students at the end of both courses, we find that, compared to the alternative strategy promoting group heterogeneity, having partners with similar skills does not help at improving the coordination between group members, nor students' perception about the usefulness of the experience towards future jobs. In fact, their rating of the overall experience was mostly the same, and, to our surprise, the partner expertise on the course topics was not a motivating factor, being that students' complaints in both cases were about not being able to pick their partners. Thus, we consider that a simple strategy to define groups (e.g. randomly) suffices, but it should be adopted on all courses since the first year of the degree.
\end{abstract}

Keywords: Working group, classroom experiment, survey, automated partner assignment.

\section{INTRODUCTION}

Nowadays, both business and public administration working environments are imposing new professional challenges to engineers, which typically require their integration into multidisciplinary working groups. It entails personal and professional interaction of specialists from different areas, and having different skills. This collaborative work, or group work, requires active participation of all of the group members, as well as implementing organizational issues, which increases the responsibility of the individuals, requiring them to develop specific group work skills.

Considering the aforementioned issues, one of the basic challenges of modern university education in general, and engineering schools in particular, is to prepare students to acquire competences in group work with the aim of being able to get fully involved in their future work environment [1]. Thus, on the one hand, the curricula of different university careers are being updated to include more transversal competences like leadership and cooperation skills within groups. On the other hand, instructors must acquire specific expertise creating actual multidisciplinary groups, which can be difficult, particularly when the available resources are limited.

For an academic instructor, a relevant aspect regarding student group composition is the chosen criteria due to the potential impact of this on the quality of results. Thus, alternatives reported in the literature fall $[2,3,4,5]$ within three different approaches depending on whether students are allowed to decide about their partners, the group members are assigned by instructor, or a random assignment method is used. Specifically, in our academic circle, we have observed a clear trend among students of grouping 
themselves by friendship affinity; moreover, this behaviour seems to become persistent throughout their studies (fact confirmed by the results presented in this paper). This shows a skewed perception of the students about the importance of teamwork and associated interpersonal skills.

In this paper we present the results of a comparative study of two strategies for workgroup composition that can be helpful for instructors to increase their alternatives for group partner assignment. The first strategy consists of creating groups where its members have very similar knowledge about the course according to results measured in previous exams. Contrarily, in the second strategy, the partners of a group are assigned so that the average exam scores of the groups were similar for all groups, which in many cases led to joining partners with antagonistic levels of knowledge.

In both methods, students are assigned by instructor. This reduces the chances of making groups based on friendship affinity, and contributes to simulate real situations of the professional environment. Furthermore, the process can be automated so that the instructor does not have to create the groups manually. The experiment was carried out in two consecutive years (one strategy each year), where students worked on a project in the scope of a Computer Engineering Degree. At the end of the course, a survey about the experience was filled out by the students, which allowed collecting and analysing data about their experiences.

The reported results show that the performance of both pairing strategies was mostly good or very good in terms of coordination and task distribution, and that only slight differences have been found among them, despite students thinking such fact is unrelated to having unusual partners. The results also confirm that, although students prefer to undertake a minimum effort strategy (same partners during the entire degree), and choose their partners themselves, they nevertheless remain aware about the need and convenience of working with a heterogeneous group of people, even though task fairness distribution is not guaranteed, as it will be the situation they will often face in the labour market.

This paper is organized as follows: in Section 2, a brief review of methods and experiences related to the problem of student assignment to groups is made. In Section 3, the characteristics of the course on which the present study was carried out are described. In Section 4, the social experiment features, hypothesis to be validated, and questions of the survey are detailed. Then, in Section 5, results are reported and analysed. Finally, conclusions are presented in Section 6.

\section{PREVIOUS WORKS ON STUDENT GROUPWORK COMPOSITION}

Attention to the topic of organizing workgroups has been profuse in the academic research literature, where a number of works analyse alternatives towards the assignment of members to workgroups based on social experiences. In this sense, the choice of a given strategy should be guided by two general goals: obtaining improvements on group performance, and contributing to a good workgroup experience for students.

Theoretical approaches for modelling the factors influencing workgroup performance span either psychological characteristics and technical skills of the individuals, as well as their specific attitude towards the group [6,7]. Particularly in academic circles, where students themselves frequently define their own group composition, additional factors like the ones derived from personal friendship and acquaintance among partners should also be considered [8,9].

One of the factors to be emphasized is the collective identification, also known as group identity or group cohesion. In fact, regarding multidisciplinary teams, some works state that, when group identity is higher, performance tends to increase [10]. Other factors rely on interpersonal relations that are necessarily established among individuals that interact in the scope of a given task. These factors should include interpersonal compatibility [11], also known as group homogeneity. Some works point out that the less compatible the group members are, the higher is the quality of results $[12,13]$.

The factors described above lead to presuppose that the criterion used to assign the workgroup membership can be relevant to succeed in academic environments, and should receive proper attention. Thus, group composition criteria are tackled in many works $[2,3,4,5]$ being grouped in three categories:

\section{i. Self-assigned teams}

Students create their own groups. It may offer higher initial cohesion [14], which can help in performance due to the short longevity of the group. Also, it may encourage students to take more ownership of group problems, motivating students to manage interpersonal conflict more successfully. Self-selected teams tend to be overly homogeneous, and thus not offer the advantages that some diversity of abilities may 
provide [15]. Self-selected teams may also possess an inadequate skill set, unless measures are taken to constrain self-selection [16].

Typically, criteria followed by students include friendship (familiarity) or ability compatibility, mutual interest (e.g., work compensation deals), physical vicinity in the classroom, or just chance. It is well known that, generally, students prefer to choose their workmates themselves (high degree of group identification.

\section{ii. Teacher-assigned teams}

Students are assigned to groups by the teacher. It can be interpreted as an attempt to "engineer" groups according to personal characteristics, such as personality, past achievements (e.g., previous scores), or relevant skills. The teacher may look for homogeneity or heterogeneity regarding personality or ability.

Teachers can get help from a number of applications implementing a diversity of optimal algorithms and heuristic approaches following a given programming model to assign members to groups $[17,18,19,20]$. Nevertheless, on the one hand, the data used are often imprecise or incomplete, and sometimes fail to capture reality. On the other hand, when using a high number of constraints and criteria, the mathematical models proposed in the literature can become extremely complex, and they can be difficult to implement. More simple criteria can be used, but in general, criteria falling in this category are less frequently used.

\section{iii. Random assignment}

Although some authors recommend random assignment because it seems fair, others have questioned this conclusion. It is clear that the final team assignments can be quite unbalanced in terms of skills, diversity, and general ability if this method is used. One can suspect that, whereas some randomly assigned teams would, by chance, end up with a desirable combination of students, others would certainly not.

Based on such diversity of criteria, a number of methods and procedures have been proposed, and numerous social experiments have been carried out to measure students' workgroup performances. Brickell et al. [21] discussed the effectiveness of five methods on course projects, including rank ordered assignment. Various criteria are also compared in [18].

An analysis of the acquaintance vs. friendship among group members is presented in [8], where groups formed by friends performed significantly better than acquaintance groups on different types of tasks because of a greater degree of group commitment and cooperation.

Bacon et al. present a statistically comprehensive study to compare a self-assigned team approach against the random method from the perspective of team experience student satisfaction [5]. The results show that self-selected teams are positively linked to best team experiences. In addition, they suggest that self-selection helps more than random assignment hurts.

Huxham and Land [22] discussed and compared the performances of student groups formed randomly against those formed using learning styles questionnaires. They did not find significant differences between these two sets of groups, and they discussed some possible reasons for this.

The objective of the research of Chapman et al. [23] was testing how random vs. student selfassignment affect the nature of group dynamics and outcomes, as well as students attitudes toward the group experience. The results indicated that the method of group member assignment has a clear influence on all those factors.

The work of Webb et al. [24] is closely related to our work. They gathered a wide sample to study group composition based on grouping different personal ability levels: below-average students, above-average students, and a mix of below and above-average students. As a conclusion, they state that, although heterogeneous (mixed) groups impose a small penalty to high-ability students, they provide a clear benefit for below-average students, thus being beneficial overall.

Contradictory conclusions have been presented while testing the effectiveness of the balanced-group assignment method (heterogeneity in skills and liabilities within the group) using the people-sequential heuristic [25], which consists of balancing groups according to the students' competence in a given field. The findings of Muller [26] showed that balanced groups have a modest advantage over groups formed randomly: students felt slightly more satisfied and shared the workload more evenly. Also, within randomly assigned groups, student perceptions of the quality of the group-project learning experience were less homogeneous. Contrarily, the results of Donohue et al. [27] indicate that most hypothesis favouring balanced groups over randomly assigned groups were not supported. 
Based on the variety of conclusions reported in the literature, achieving an optimal group assignment strategy can still be considered an open issue. In this paper we expect to contribute with additional information from a new social experiment where two opposing strategies are compared: membership based on similar knowledge of the course subject, and membership based on dissimilar knowledge.

\section{BRIEF OVERVIEW OF THE TARGET COURSE}

Design and Configuration of Local Area Networks (DCLAN) is a mandatory course for all those students enrolled at the Technical University of Valencia (UPV) in the Degree on Informatics upon selecting the Information Technology (IT) specialization. In the scope of the Degree on Informatics, the DCLAN course contributes significantly to major degree competences such as:

- Knowledge and application of the features, functionality and structure of Distributed Systems, Computer Networks and the Internet.

- Ability to design systems, applications and services based on network technologies, including the Internet, web, e-commerce, multimedia, interactive services and mobile computing.

In addition, it also contributes to transversal competences including (i) comprehension and integration, (ii) application and practical thinking, (iii) specific hardware, and (iv) group work and leadership, being that this last competence receives a special focus in this work.

As an IT specialization course, it aims at developing a profound comprehension about the functioning and management of commercial Local Area Network (LAN) devices, including the most widely deployed technologies (IEEE 802.3 and its variants, IEEE 802.11 and its variants) and protocols (VLAN, STP/RSTP, etc.), including security-related issues. A brief overview of access technologies and other LAN standards is also provided.

The DCLAN course takes place in the sixth semester of the degree ( $3^{\text {rd }}$ year) for a period ranging from February to May, and it is endowed with 4.5 ECTS credits. These 4.5 credits are split into theoretical class credits (3 ECTS) and lab session credits (1.5 ECTS).

Theoretical classes take place every week as a single 2-hour session. During these sessions the instructor conveys information to students using slides, videos and the blackboard, which are interleaved with frequent quizzes and short tests for students. Lab sessions also take place once every week. During lab sessions, students have direct contact with networking hardware such as access points and highperformance switches to perform management tasks. In addition, students also carry out network simulations to gain awareness about the performance of the different network technologies under different loads, among other goals.

Concerning evaluation, a total of 5 evaluation events are defined, 2 of them related to the contents of theoretical classes, and 3 related to the contents of lab sessions. The details about these different evaluation events are presented in Table 1.

Table 1. Evaluation events.

\begin{tabular}{|c|l|c|c|}
\hline Related to: & \multicolumn{1}{|c|}{ Number/type } & Score weight (\%) & Evaluation dates \\
\hline $\begin{array}{c}\text { Theory } \\
\text { sessions }\end{array}$ & 2 written exams (open answer) & $60 \%$ & March/June \\
\hline \multirow{2}{*}{ Lab sessions } & 2 multiple-choice exams & $20 \%$ & March/June \\
\cline { 2 - 4 } & 1 group project & $20 \%$ & May \\
\hline
\end{tabular}

In this paper we focus specifically on the group project undertaken during the course. This group project, which addresses the configuration of network devices using a simulation tool, requires the joint work of 2 (or in exceptional cases 3 ) students. Group members must be working together or in a perfectly coordinated manner to complete the project successfully. Additionally, copy prevention mechanisms are 
deployed in order to prevent fraud. In the next section we detail the experiments using working groups, along with the main hypothesis we wanted to confirm or disprove.

\section{HYPOTHESIS AND METHODOLOGY}

Groupwork is a work strategy offering many benefits such as increased productivity and performance, enhanced communication skills, improved time management and planning, and gaining more selfawareness. In fact, groupwork skills are positively evaluated by most organizations during personnel recruitment ¡Error! No se encuentra el origen de la referencia..

To address the organization requirements in the professional sector, groupwork skills are nowadays integrated into the curricula of different university degrees, and evaluating students' skills on such area is becoming critical, receiving much emphasis from degree certification authorities. At the Technical University of Valencia, the Degree on Informatics is a clear example of this new paradigm, being groupwork one of the main competences defined.

A possible problem concerning groupwork skill acquisition in the university is that students may pick the same colleagues for groupwork over and over again, thereby failing to accomplish critical adaptability and communication skills that are typically gained when facing heterogeneous elements in the group, each having a different work style. If this occurs, we believe that the groupwork competence currently defined for the degree will not be achieved to its fullest extent, as desirable. In addition, we believe that students are not fully aware of this shortage, which will only become evident when they graduate and start working on a company requiring such skills.

In this work we try to address this problem, and so we formulate the following hypothesis:

H1. When allowed to pick their own partner(s), students tend to choose partners with similar skills, and they typically maintain the same group partner(s).

H2. Forcing a change of partner is prone to cause resistance and problems to students, which are not adaptable as expected.

H3. The option of joining two students with a same knowledge about the course has a bigger impact on overall workgroup experience than the alternative option (dissimilar knowledge in most cases).

H4. The option of joining two students with a same knowledge about the course promotes a more even task distribution than the alternative option (dissimilar knowledge in most cases).

H5. Although students are aware of the relevance of groupwork skills when joining the labour market in a near future, they fail to understand how important it is to work with different project partners in order to properly acquire these skills.

In the scope of the DCLAN course, groupwork is promoted through a group project that is performed outside class periods, and that requires perfect student coordination, as referred above. In this work, and using the group project as our target population, we perform a social experiment to confirm or disprove the different hypothesis presented above, to check whether project tasks are evenly distributed among group members, and to obtain feedback about students' perception concerning the experiment. To achieve this, in our experiment students are assigned to instructor-defined groups. In particular, we will compare two group definition strategies. The first strategy, which will be tagged as "Same skills" in the results that follow, consists of creating groups where its members have very similar knowledge about the course according to the average exam results. This way, if we have a group of $n$ students (assumed even for the sake of simplicity), where the highest scoring student is in the first position, and the lowest ranked student is in the last position $(n)$, students are paired as follows: $(1,2),(3,4),(4,5), \ldots,(n-1, n)$. Concerning the second strategy, which will be tagged as "Opposed skills" in the results that follow, consists of creating groups where the group average exam results for all groups are quite similar. If we have a group of $n$ students, where again the highest scoring student is in the first position, and the lowest ranked student is in the last position $(n)$, this is achieved by pairing students as follows: $(1, n),(2, n-1)$, $(3, \mathrm{n}-2), \ldots,(\mathrm{n} / 2, \mathrm{n} / 2+1)$.

The first proposed strategy was tested during course 2013-2014, while the second strategy was tested during course 2014-2015. To gather all required results, the participants answered to an online survey addressing the concerns presented above. During the last lab session of the course, where the different workgroups also presented their work. The most relevant survey questions to our purposes were the following: 
Q1. How many group projects have you made to date?

Q2. How was your group partner(s) selected in previous projects?

Q3. Concerning the group partner(s) for the current project, did you work together in previous projects?

Q4. Rate the degree of coordination with your group partner(s) in the current project.

Q5. How would you describe your experience of working with your partner in this project?

Q6. How evenly were tasks distributed among participants in previous projects?

Q7. How evenly were tasks distributed among participants in this project?

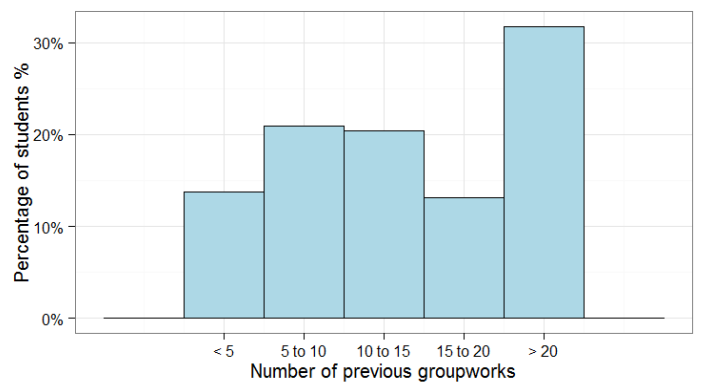

Figure 1: Number of groupworks during college.

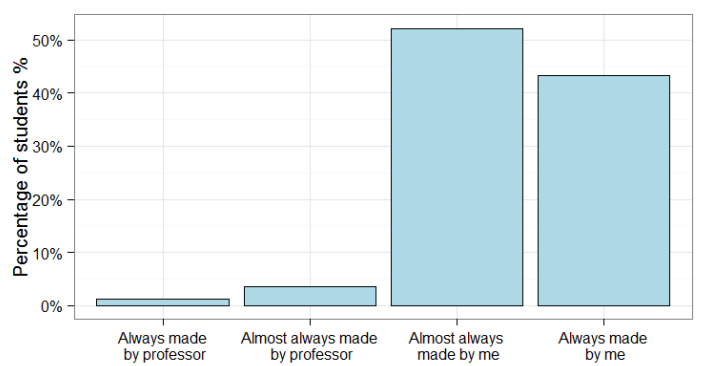

Figure 2: Who defined the working groups?

Q8. Do you think that working with a project partner for the first time helps at achieving an even task distribution?

Q9. Concerning your future work within an organization, how useful do you think this groupwork experience will be?

Once completed, we processed the answers' database obtained using the $\mathrm{R}$ tool. The output of such statistical analysis is presented in the next section.

\section{RESULTS AND DISCUSSION}

In this section we present the results of our survey, discussing the validity of the different hypothesis. The charts contain information about the two surveys. Data from different surveys has been represented as only one experiment when we estimated that the student's answers were not influenced by the matching rule. We also assumed that both classes were equivalent and that no external factor influenced the experiment.

To check the first hypothesis, that is, "students have worked several times in different group projects, but they were allowed to pick their own partners", we asked questions 1 and 2.

Figure 1 shows the results for Question 1. It can be seen that nearly $35 \%$ of the students have participated in more than 20 groupworks during their university studies, while only less than $13 \%$ of the students claim to have participated in less than 5 groupworks. Such results evidence that, throughout their degree, students usually participate, on average, in 3.6 groupworks per semester. So, the overall number of groupworks is enough to guarantee their familiarity with this type of activity, and also with working with other colleagues. However, as figure 2 shows, the impact of these activities is reduced because, in the majority of cases, students define groups by themselves and, as students themselves confirm, they tend to pick the same partner whenever possible (see Figure 3). This is rather expectable since friendship and familiarity generate a more comfortable situation to students, being optimal in the sense of minimizing effort and uncertainty. Thus, only the instructor is able to introduce some chaos in this sustained behaviour by forcing changes. As stated in the previous section, in this paper we study two alternatives providing automated group creation so that the instructor does not have to create the groups manually. 


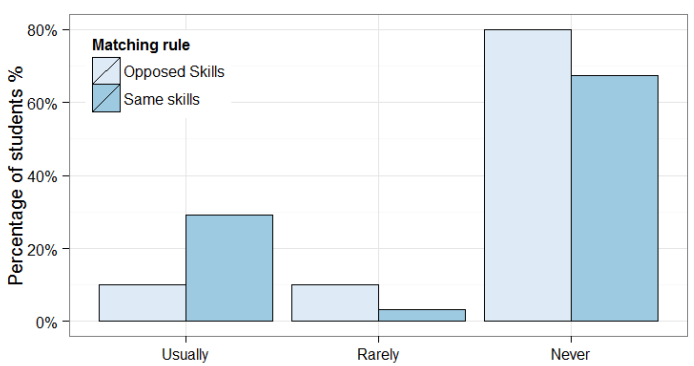

Figure 3: Project partner previous working frequency.

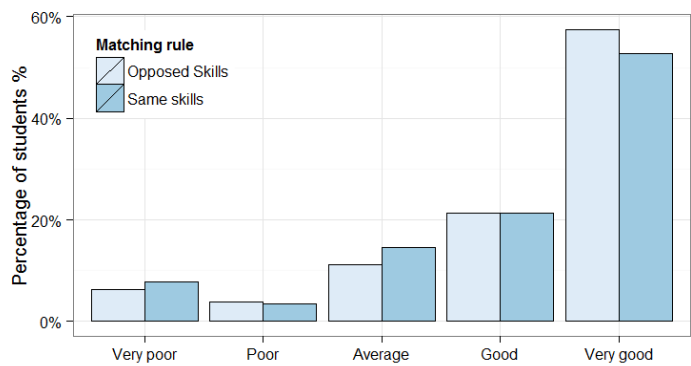

Figure 4: Coordination with the project partner in the current project.

Concerning Question 2, figure 2 shows that students were allowed to choose their partners about $90 \%$ of the times. Only a $5 \%$ of the students claim that the teacher was the one defining the groups. Based on the results of both figures, we confirm the first hypothesis.

Since for the DCLAN course project partners where defined by the instructor, more than $65 \%$ of the students answering to Question 3 claim that project partners were new to each other, while only less than $30 \%$ of the students were coupled with a previous partner (see figure 3). Comparing both strategies, we notice that, when using the "Opposed skills" rule, more students claim that they had never worked with their partners.

In both years, the change of partner caused several students to orally transmit to instructors their discomfort about working with new partners, validating the second hypothesis. Despite their lack of comfort, students state that the coordination between partners was "Good" or "Very good" for the majority, while cases of "Poor" $/$ "Very poor" coordination are scarce (see figure 4). Contrary to what we may expected, students with "Opposed skills" coordinated slightly better than students with "Same skills".

The same trend is noticeable in answers to Question 5 (see figure 5), evidencing that the work experience with a new partner was "Good" or "Very good" in most cases, although some students had a very bad experience with the new partner. Again, we notice that students claim that their experience when the "Opposed skills" strategy was applied was slightly better than when applying the "Same skills" strategy.

If we focus on task distribution fairness, student answers to questions 6 and 7 show that both new partner assignment methods allow distributing tasks more evenly compared to previous projects. Specifically, answers to Question 6 (see Figure 6) evidence that, although about 20\% of students consider that the task distribution in previous projects was "Very good", still a significant number of students think that the distribution was "Average" ( 25\%) or even worse $(\sim 15 \%)$. On the contrary, answers to Question 7 show that, when the instructor defines the groups, a greater number of students believe that the task distribution was very good. When using the "Opposed skills" matching rule, there are more students that claim their task distribution fairness was "Poor" or "Very Poor", suggesting that the "Opposed skills" rule may be the riskier option when creating new working groups.

Concerning Question 8, we find that, despite students have achieved a better workload distribution in this project, they have different opinions about whether having a new partner helps to evenly distribute the workload (see figure 7). In general, students believe that fairness was not strictly related to this factor. In general, students do not believe that having new partners helped to achieve a better workload distribution, believing it was pure chance. Surprisingly, when the "Opposed skills" matching rule was used, more students agreed that having new partners promotes a fair task distribution. 


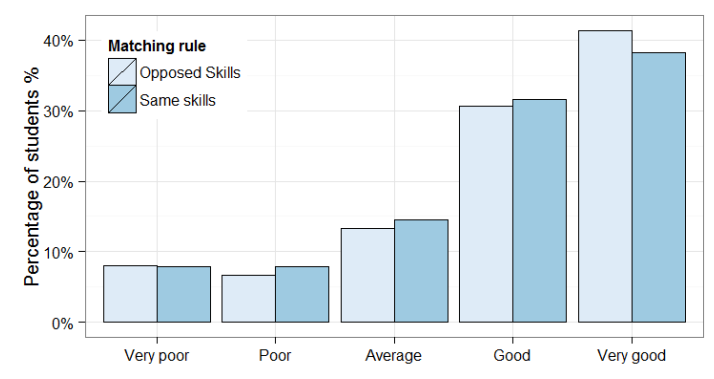

Figure 5: Workgroup experience in the project.

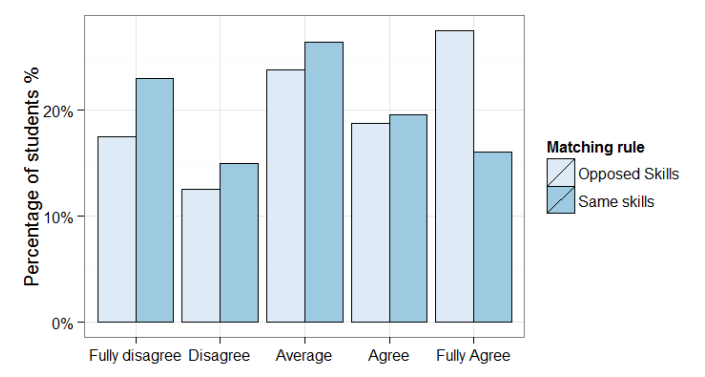

Figure 7: Having new partners promotes a fair task distribution.

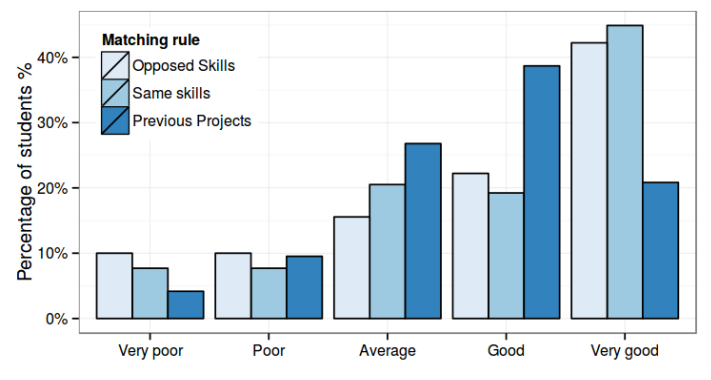

Figure 6: Task distribution fairness among students.

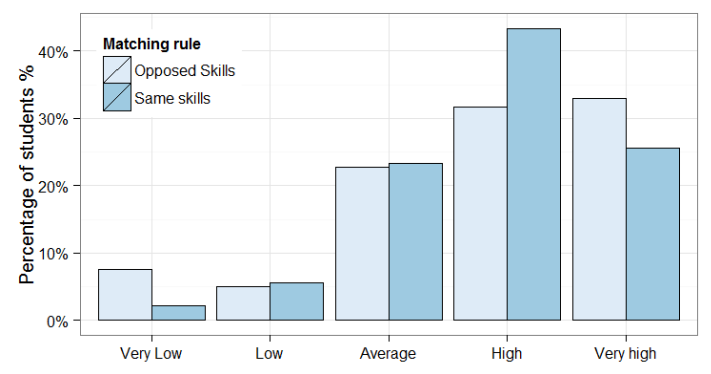

Figure 8: Usefulness of the groupwork experience in future jobs.

Finally, concerning Question 9, figure 8 shows that, for both matching rules, about $70 \%$ of the students consider that this groupwork experience will be of a "High" or "Very high" usefulness for their future, as it implies working with people that may not be a friend or usual companion. Such results partially disprove hypothesis 5 , meaning that students do find the experience of working with partners as being helpful when facing future jobs. We believe this finding is quite positive since it means that, although students prefer to undertake a minimum effort strategy (same partners during the entire degree), they remain aware about the need and convenience, as future professionals, of working with a heterogeneous group of people, despite task fairness distribution is not guaranteed, as it will be the situation they will often face in the labour market.

\section{CONCLUSIONS AND FUTURE WORK}

Groupwork is one of the most sought-after skills for recruiters as it involves interpersonal skills as well as organizational skills. Therefore, it is important for engineering students to acquire habits and experience in this skill.

Nowadays, although engineering students are involved in lots of different group projects, we find that the groupwork skill is not being properly developed as students are allowed to select their partners. As a result, groups remain mostly the same year after year.

In this work, we present the results of a two-year study where students were forced to team up with other partners based on the results of a networking-skills ranking exam. In the first experiment (year 1) they were paired with partners with the same skills, while in the second experiment (year 2) they were paired with partners with opposed skills. These pairing methods also permit to break previous persistent partnerships, creating an environment more similar to one they could encounter in a future job, where some team manager may define the different working groups.

Experimental results confirm that, in our academic circle, groups are usually conformed by the same students, and that students tend to resist to partner changes. By enforcing new group partners, we find that workload distribution was improved. Also, despite facing initial complaints about having new partners, results also show that, in general, the experience and coordination with the new partner was very positive. We also found slight differences between the used pairing strategies: the "Opposed skills" 
strategy seems to deliver better results in most groups, but also presents a small increment of cases reporting "Very Poor" coordination and task distribution. Therefore, the "Opposed skills" strategy seems to be riskier than the "Same skills" strategy.

Overall, no matter the pairing strategy, most students considered that having new group partners was a useful experience, allowing them to better prepare for future job conditions.

As a future work, we plan to extend our experiment to bigger groups and different courses, that so we can achieve more conclusive results.

\section{ACKNOWLEDGMENTS}

This work was partially supported by the School of Informatics (ETSINF) and the Department of Computer Engineering (DISCA) at the Universitat Politècnica de València.

\section{REFERENCES}

[1] Baker, D.P., Day, R. and Salas, E. (2006), Teamwork as an Essential Component of HighReliability Organizations 41(4), pp. 1576-1598.

[2] Weitz, R.R. and Jelassi, M.T. (1992). Assigning Students to Groups: A Multi-Criteria Decision Support System Approach. Decision Sciences 23(3), pp. 746-757.

[3] Brickell, J.L., Porter, D.B., Reynolds, M.F., and Cosgrove, R.D. (1994). Assigning Students to Groups for Engineering Design Projects: A Comparison of Five Methods. Journal of Engineering Education, 83(3), 259-262.

[4] Baker, K.R. and Powell, S.G. (2002). Methods for Assigning Students to Groups: A Study of Alternative Objective Functions. Journal of the Operational Research Society 53(4), pp. 397-404.

[5] Bacon, D.R., Stewart, K.A. and Silver, W.S (1999). Lessons from the Best and Worst Student Team Experiences: How a Teacher can make the Difference. Journal of Management Education, 23(5), pp-467-488.

[6] Thamhain, H. J. and Wilemon, D. L. (1987). Building High Performing Engineering Project Teams. IEEE Transactions on Engineering Management 34(3), pp.130-137.

[7] Chen, S. and Lin, L. (2004). Modeling Team Member Characteristics for the Formation of a Multifunctional Team in Concurrent Engineering. IEEE Transactions on Engineering Management 51(2), pp. 111-123.

[8] Jehn, K.A.; Shah, P.P. (1997). Interpersonal Relationships and Task Performance: An Examination of Mediation Processes in Friendship and Acquaintance Groups. Journal of Personality and Social Psychology 72(4), pp. 775-790.

[9] Gruenfeld, D. H., Mannix E.A., Williams, K. Y. and Neale, M.A. (1996). Group Composition and Decision Making: How Member Familiarity and Information Distribution Affect Process and Performance. Organizational Behavior and Human Decision Processes 67(1), pp. 1-15.

[10] Van Der Vegt, G.S. and Bunderson, J.S. (2005). Learning and Performance in Multidisciplinary Teams: The Importance of Collective Team Identification. The Academy of Management Journal 48(3), pp. 532-547.

[11] Harrison, R. and Lubin, B. (1965) Personal Style, Group Composition, and Learning. The Journal of Applied Behavioral Science 1, pp. 286-301.

[12] Hill, R. E. (1975). Interpersonal Compatibility and Workgroup Performance. The Journal of Applied Behavioral Science 11, pp. 210-219.

[13] Hoffman, L. Richard (1959). Homogeneity of member personality and its effect on group problemsolving. The Journal of Abnormal and Social Psychology 58(1), pp. 27-32.

[14] Strong, J.T. and Anderson, R.E. (1990). Free-riding in group projects: Control mechanisms and preliminary data. Journal of Marketing Education 12, pp. 61-67.

[15] Bacon, D.R., Stewart, K.A., and Stewart-Belle, S. (1998). Exploring predictors of student team project performance. Journal of Marketing Education 20(1), pp. 63-71. 
[16] Mello, J.A. (1993). Improving individual member accountability in small work group settings. Journal of Management Education 17(2), pp. 253-259.

[17] Weitz, R.R. and Jelassi, M.T. (1992). Assigning Students to Groups: A Multi-Criteria Decision Support System Approach. Decision Sciences 23(3), pp. 746-757.

[18] Baker, K.R. and Powell, S.G. (2002). Methods for Assigning Students to Groups: A Study of Alternative Objective Functions. Journal of the Operational Research Society 53(4), pp. 397-404.

[19] Graf, S. and Bekele R. (2006). Forming Heterogeneous Groups for Intelligent Collaborative Learning Systems with Ant Colony Optimization. In Proceedings of the Intl. Conf. on Intelligent Tutoring Systems, pp. 217-226.

[20] Cavanaugh, R., Ellis, M., Layton, R., and Ardis, M. (2004). Automating The Process of Assigning Students to Cooperative-Learning Teams. In Proceedings of the 2004 ASEE Annual Conference.

[21] Brickell, J.L., Porter, D.B., Reynolds, M.F., and Cosgrove, R.D. (1994). Assigning Students to Groups for Engineering Design Projects: A Comparison of Five Methods. Journal of Engineering Education, 83(3), 259-262.

[22] Huxham, M., Land, R. (2000). Assigning Students in Group Work Projects. Can We Do Better than Random?. Innovations in Education \& Training International 37(1), pp. 17-22.

[23] Chapman K.J., Meuter M., Toy D. and Wright R. (2006). Can't We Pick our Own Groups? The In uence of Group Selection Method on Group Dynamics and Outcomes, Journal of Management Education 30(4), pp. 557-569.

[24] Webb, N.M., Nemer, K.M. and Chizhik, A.W. (1998). Equity Issues in Collaborative Group Assessment: Group Composition and Performance. American Educational Research Journal 35, pp. 607-651.

[25] Beheshtian-Ardekani, M. and Mahmood, M.A. (1986). Development and Validation of a Tool for Assigning Students to Groups for Class Projects. Decision Sciences 17, pp. 92-113.

[26] Muller, T. E. (1989). Assigning Students to Groups for Class Projects: An Exploratory Test of Two Methods. Decision Sciences 20(3), pp. 623-634.

[27] Donohue, J.M. and Fox, J.B. (1993). An Investigation into the People-Sequential Heuristic Method of Group Formation. Decision Sciences 24(2), pp.493-509. 